\title{
Estimativa do filocrono em milho para híbridos com diferentes ciclos de desenvolvimento vegetativo
}

\author{
Estimating the phyllocron in maize hybrids with different cycles of vegetative development \\ Juliano Dalcin Martins ${ }^{{ }^{*}}$ Reimar Carlesso $^{\text {II }}$ Mirta Terezinha Petry $^{\text {II }}$ Alberto Eduardo Knies ${ }^{\mathrm{I}}$ \\ Zanandra Boff de OliveiraI ${ }^{\mathrm{I}}$ Tiago Broetto ${ }^{\mathrm{III}}$
}

RESUMO

O filocrono é definido como o tempo térmico necessário para o aparecimento de folhas sucessivas na haste principal de uma planta. Através do filocrono, pode-se calcular a duração do período vegetativo e, portanto, a época de florescimento em função da temperatura do ar. O presente trabalho teve por objetivo determinar o filocrono de diferentes híbridos de milho. Foram conduzidos três experimentos a campo, nos anos agrícolas de 2007/08, 2008/09 e 2009/2010. $O$ delineamento experimental foi o de blocos ao acaso com três repetições. Os tratamentos constituíram-se de 18, 22 e 24 híbridos de milho, nos anos agrícolas de 2007/08, 2008/09 e 2009/2010, respectivamente. O filocrono foi estimado pelo inverso do coeficiente angular da regressão linear entre o número de folhas e a soma térmica acumulada a partir de emergência (temperatura base $=10^{\circ} \mathrm{C}$ ). O filocrono calculado variou de 44,3 a 34,4 ${ }^{\circ} \mathrm{C}$ dia $^{-1}$ folha ${ }^{-1}$ entre os híbridos avaliados, estando o valor de filocrono dos híbridos diretamente relacionados com a precocidade do período vegetativo.

Palavras-chave: emissão de folhas, soma térmica, desenvolvimento vegetal, Zea mays.

\section{ABSTRACT}

The phyllochron is defined as the thermal time needed for the appearance of successive leaves on the plant main stem. Through the phyllochron it is possible to calculate the length of the growing period and thus the flowering period based on the air temperature. This study aimed to determine the phyllochron from different maize hybrids. Three field experiments were carried out during the agricultural years of 2007/08, 2008/09 and 2009/2010. The experimental design was one of randomized blocks with three repetitions. The treatments consisted of 18, 22 and 24 maize hybrid during the three agricultural years of 2007/08, 2008/09 and 2009/2010, respectively. The phyllochron was estimated by the inverse of the angular coefficient of the linear regression between the number of leaves and the accumulated thermal sum from emergence on (base temperature $=10^{\circ} \mathrm{C}$ ). The calculated phyllochron varied from 44.3 to $34.4^{\circ} \mathrm{C}$ day $^{-1}$ leaf $f^{-1}$ among the evaluated hybrids, being the phyllochron value of hybrids directly related to the precocity of the growing period.

Key words: appearance leaves, thermal time, plant development, Zea mays.

\section{INTRODUÇÃO}

No desenvolvimento das plantas de milho, a duração do ciclo em dias é inconsistente, pois a duração de subperíodos da planta está associada às condições ambientais, e não ao número de dias. A temperatura do ar é o elemento meteorológico que melhor explica a duração dos períodos de desenvolvimento do milho, havendo relação linear entre a duração desses períodos e o desenvolvimento da planta (LOZADA \& ANGELOCCI, 1999). A interação da cultura com outros fatores como água, nitrogênio e fotoperíodo pode provocar alterações na duração do ciclo de desenvolvimento e fases, sob diferentes ambientes. Entretanto, o somatório em graus dia que representa o efeito da temperatura do ar sobre o

IPrograma de Pós-graduação em Engenharia Agrícola, Centro de Ciências Rurais (CCR),Universidade Federal de Santa Maria, (UFSM), 97105-900, Santa Maria, RS, Brasil. E-mail: julianodalcinmartins@gmail.com. *Autor para correspondência.

"Departamento de Engenharia Rural, CCR, UFSM, Santa Maria, RS, Brasil.

IIIPrograma de Pós-graduação em Ciência do Solo, Universidade Federal do Rio Grande do Sul, (UFRGS), Porto Alegre, RS, Brasil. 
crescimento e desenvolvimento das plantas tem sido a variável adequada para estimar eventos fenológicos em milho (BERGAMASCHI \& MATZENAUER, 2009). A maneira de incluir a temperatura do ar no tempo vegetal é utilizar a soma térmica, definida como o acúmulo térmico, acima de uma temperatura base, necessária para que a planta atinja um determinado estádio fenológico de desenvolvimento (NESMITH \& RITCHIE, 1992).

A velocidade de emissão de folhas no colmo é um importante parâmetro do desenvolvimento vegetal. Ao integrar a velocidade de emissão de folhas no tempo, tem-se o número de folhas acumuladas, que é um importante parâmetro do desenvolvimento vegetativo das culturas agrícolas (STRECK et al., 2007), que, no milho, está relacionado com o surgimento de vários estádios de desenvolvimento (FORSTHOFER et al., 2004). Para calcular o aparecimento de folhas no colmo de plantas, determina-se o filocrono, que é o intervalo de tempo térmico em graus-dia, entre a emissão de folhas com estádios similares de desenvolvimento (XUE et al., 2004).

O registro do aparecimento de folhas no colmo da planta é uma medida de tempo fisiológico, o qual está associado ao momento de ocorrência dos diferentes estádios de desenvolvimento de diversas espécies vegetais. Além da evolução da área foliar da planta, a iniciação, a diferenciação e o aparecimento de muitos órgãos em espécies da família das Poáceas, como o milho, estão relacionados com o número de folha, como o início e o fim da diferenciação dos primórdios florais (McMASTER et al., 1991).

O valor do filocrono em milho pode variar com a época de semeadura (STRECK et al., 2009) e com o déficit hídrico (SOLER et al., 2005). Entretanto, pouco se sabe da variação do filocrono entre híbridos de milho e seus diferentes ciclos de desenvolvimento. A caracterização do desenvolvimento de diferentes híbridos é um tema relevante e contínuo de pesquisa. Dessa forma, o presente estudo teve por objetivo determinar o filocrono para diferentes híbridos de milho e sua relação com a precocidade de cada híbrido.

\section{MATERIAL E MÉTODOS}

Três experimentos foram conduzidos a campo, em área experimental do Departamento de Engenharia Rural da Universidade Federal de Santa Maria, Santa Maria, RS, localizada na Depressão Central do Rio Grande do Sul, Latitude 29³3'S, Longitude de 534' 'W e altitude de 95m, nos anos agrícolas de 2007/ 08, 2008/09 e 2009/10. O delineamento experimental utilizado foi o de blocos ao acaso com três repetições.
Os tratamentos constituíram-se de diferentes híbridos (Tabela 1). No ano agrícola de 2007/08, foram utilizados dezoito híbridos de milho, no ano agrícola de 2008/09 vinte e dois e no ano agrícola de 2009/10 vinte e quatro híbridos, selecionados por representarem genótipos de ciclos de desenvolvimento distintos, conforme FANCELLI \& DOURADO-NETO (2000) e pela disponibilidade em cada ano agrícola.

No ano agrícola 2007/08 e 2008/09, a unidade experimental foi formada por oito linhas de cultivo com quatro metros de comprimento e, em 2009/10, por sete linhas de cultivo com cinco metros de comprimento. $\mathrm{O}$ espaçamento entre linhas foi de $0,45 \mathrm{~m}$, com densidade de 7 plantas por $\mathrm{m}^{2}$. A adubação, para a cultura do milho, foi realizada de acordo a COMISSÃO DE QUÍMICAE FERTILIDADE DO SOLO-RS/SC (2004).

As semeaduras foram realizadas manualmente, após a demarcação das linhas de cultivo e distribuição dos fertilizantes por uma semeadora mecânica, em sistema de plantio direto sob resíduos culturais de aveia preta em 06/11/2007, 10/10/2008 e 11/ 11/2009. A emergência das plântulas foi determinada contando-se diariamente o número de plantas visíveis acima do nível do solo, considerando a emergência quando $50 \%$ das plântulas estavam visíveis. A emergência ocorreu em 12/11, 20/10 e 17/11, respectivamente, para os anos agrícolas de 2007/08, 2008/09 e 2009/10. Logo após a emergência, foram identificadas duas plantas nas linhas centrais de cada parcela e realizada a contagem do número de folhas completamente expandidas (com o colar visível, NFE) a cada dois dias (RITCHIE et al., 1993). Cada planta marcada foi considerada uma amostra da parcela e a média das plantas marcadas em cada parcela foi considerada uma repetição, conforme STRECK et al. (2005).

A necessidade de irrigação foi determinada com base na estimativa da evapotranspiração de referência pelo método de Penman-Monteith, com os valores de coeficientes de cultura recomendados por ALLEN et al. (2006). Irrigações foram aplicadas quando a evapotranspiração máxima indicava valores acumulados de $32 \mathrm{~mm}$.

As lâminas de irrigação aplicadas desde o período da semeadura até a maturação fisiológica foram de 256, 308 e $120 \mathrm{~mm}$, respectivamente, para os anos agrícolas de 2007/08, 2008/09 e 2009/10. As irrigações foram complementares à precipitação pluvial que, entre a semeadura e a maturação fisiológica, foi de 563, 401 e $1150 \mathrm{~mm}$, respectivamente, para os anos agrícolas de 2007/08, 2008/09 e 2009/10.

Os dados meteorológicos diários de temperatura do ar e radiação solar foram obtidos por uma estação meteorológica automática, localizada 
Tabela 1 - Filocrono $\left({ }^{\circ} \mathrm{C}\right.$ dia $^{-1}$ folha $\left.{ }^{-1}\right)$ de híbridos de milho nos anos agrícolas de 2007/08, 2008/09 e 2009/10 . Santa Maria, RS.

\begin{tabular}{|c|c|c|c|c|c|c|c|c|c|c|c|}
\hline \multirow{2}{*}{$\begin{array}{l}\text { Híbrido } \\
\text { 2B587 }\end{array}$} & \multicolumn{2}{|c|}{ Filocrono } & \multirow{2}{*}{$\frac{\mathrm{R}^{2}}{0.99}$} & \multirow{2}{*}{$\begin{array}{l}\text { Híbrido } \\
\text { BG7055* }\end{array}$} & \multicolumn{2}{|c|}{ Filocrono } & \multirow{2}{*}{$\frac{\mathrm{R}^{2}}{0.98}$} & \multirow{2}{*}{$\begin{array}{l}\text { Híbrido } \\
\text { AG8041 }\end{array}$} & \multicolumn{2}{|c|}{ Filocrono } & \multirow{2}{*}{$\frac{\mathrm{R}^{2}}{0.99}$} \\
\hline & $40,2 \mathrm{a}$ & SP & & & $43,1 a^{n s}$ & $\mathrm{~T}$ & & & $44,3 a$ & $\mathrm{P}$ & \\
\hline 2A525 & $39,9 a$ & SP & 0.99 & RB 9108 & $42,8 a$ & $\mathrm{~T}$ & 0.98 & BG8124 & $44,0 \mathrm{a}$ & $\mathrm{P}$ & 0.99 \\
\hline 2B707 & 39,3а & $\mathrm{P}$ & 0.99 & DKB390 & $42,6 a$ & $\mathrm{P}$ & 0.97 & AG8025 & $44,0 \mathrm{a}$ & SP & 0.99 \\
\hline 30F53 & $39,2 \mathrm{a}$ & $\mathrm{P}$ & 0.98 & BRS3060 & $42,4 a$ & $\mathrm{~T}$ & 0.99 & $30 \mathrm{~S} 31^{*}$ & $43,8 a^{n s}$ & $\mathrm{P}$ & 0.99 \\
\hline 2B688 & $39,0 \mathrm{a}$ & SP & 0.99 & $30 \mathrm{~S} 31^{*}$ & $42,2 a^{n s}$ & $\mathrm{P}$ & 0.97 & BG7055* & $43,3 \mathrm{a}^{\mathrm{ns}}$ & $\mathrm{T}$ & 0.99 \\
\hline AG8088 & $38,9 a$ & SP & 0.99 & 30В30 & $42,1 \mathrm{a}$ & $\mathrm{P}$ & 0.98 & $30 \mathrm{R} 50$ & $43,0 a$ & $\mathrm{P}$ & 0.98 \\
\hline AS1575 & $37,9 b$ & SP & 0.99 & P3862* & $42,0 \mathrm{a}^{\mathrm{ns}}$ & $\mathrm{P}$ & 0.99 & BG8418 & $42,8 a$ & SP & 0.98 \\
\hline 30F36 & $37,7 b$ & $\mathrm{P}$ & 0.99 & 30В39* & $41,9 a^{n s}$ & $\mathrm{P}$ & 0.98 & 30F87 & $42,2 b$ & $\mathrm{~T}$ & 0.99 \\
\hline AG8015 & $37,6 b$ & SP & 0.99 & BG7049* & $41,7 a^{\mathrm{ns}}$ & $\mathrm{P}$ & 0.98 & AG9045 & $42,1 b$ & SP & 0.98 \\
\hline AG8021* & $37,4 b^{\mathrm{ns}}$ & SP & 0.99 & BRS1001 & $41,1 \mathrm{a}$ & $\mathrm{P}$ & 0.98 & BG7051 & $41,9 b$ & $\mathrm{P}$ & 0.98 \\
\hline 32R48 & $37,4 \mathrm{~b}$ & HP & 0.99 & 2B287 & $41,0 \mathrm{a}$ & $\mathrm{P}$ & 0.96 & BG7049* & $41,8 b^{\mathrm{ns}}$ & $\mathrm{P}$ & 0.99 \\
\hline DKB177 & $37,0 \mathrm{c}$ & $\mathrm{P}$ & 0.99 & BR 206 & $40,8 a$ & $\mathrm{P}$ & 0.98 & AS 1551 & $41,7 b$ & SP & 0.99 \\
\hline AS1565 & $36,4 c^{\mathrm{ns}}$ & SP & 0.99 & DKB250 & $40,2 b$ & $\mathrm{SP}$ & 0.96 & 30B39* & $41,6 b^{\mathrm{ns}}$ & $\mathrm{P}$ & 0.99 \\
\hline 32R21 & $36,0 \mathrm{c}$ & HP & 0.98 & BG7060* & $39,9 b^{\mathrm{ns}}$ & $\mathrm{P}$ & 0.97 & DKB566 & $41,5 b$ & SP & 0.99 \\
\hline AG9020 & $35,4 \mathrm{c}$ & HP & 0.99 & AG7088 & $39,7 b$ & $\mathrm{~T}$ & 0.99 & BG7060* & $41,5 b^{\mathrm{ns}}$ & $\mathrm{P}$ & 0.99 \\
\hline 2A106 & $35,4 c$ & HP & 0.99 & RB 9308 & $39,4 b$ & $\mathrm{SP}$ & 0.97 & P3340 & $41,4 b$ & $\mathrm{P}$ & 0.98 \\
\hline DKB240 & $35,3 c$ & HP & 0.98 & AS1557 & $39,2 b$ & HP & 0.97 & AG9010 & $41,2 b$ & SP & 0.99 \\
\hline \multirow[t]{7}{*}{ 2A120 } & $34,4 \mathrm{c}$ & HP & 0.99 & P3646* & $39,1 b^{\text {ns }}$ & $\mathrm{P}$ & 0.98 & P3862* & $41,0 \mathrm{~b}^{\mathrm{ns}}$ & $\mathrm{P}$ & 0.96 \\
\hline & & & & AS1565 ${ }^{*}$ & $38,7 b^{\mathrm{ns}}$ & $\mathrm{SP}$ & 0.97 & DKB330 & $40,8 b$ & $\mathrm{P}$ & 0.99 \\
\hline & & & & AG8011 & $38,7 b^{\mathrm{ns}}$ & $\mathrm{P}$ & 0.97 & P1630 & $40,6 b$ & SP & 0.98 \\
\hline & & & & P2323 & $37,7 b$ & SP & 0.96 & 32R22 & $40,4 b$ & SP & 0.98 \\
\hline & & & & Fórmula & $37,7 b$ & HP & 0.97 & AG8011 ${ }^{*}$ & $40,4 b^{\mathrm{ns}}$ & $\mathrm{P}$ & 0.98 \\
\hline & & & & & & & & P3646* & $40,3 b^{\mathrm{ns}}$ & $\mathrm{P}$ & 0.98 \\
\hline & & & & & & & & AG8021* & $39,2 b^{\text {ns }}$ & SP & 0.98 \\
\hline Média & 37,5 & & & & 40,6 & & & & 41,8 & & \\
\hline CV (\%) & 2,34 & & & & 2,99 & & & & 2,86 & & \\
\hline Dp & 1,39 & & & & 1,72 & & & & 1,40 & & \\
\hline
\end{tabular}

Médias seguidas pela mesma letra não diferem entre si pelo teste de Scott-Knott a 5\% de probabilidade de erro; ${ }^{\text {ns }}$ Médias do filocrono não diferem pelo teste $\mathrm{t}$ a $(\mathrm{P}<0,05)$ entre os anos agrícolas em que o híbrido se repete; * Híbridos que se repetem entre anos agrícolas; $\mathrm{CV}$ (coeficiente de variação); Dp (desvio padrão); HP (híbrido hiperprecoce); SP (superprecoce); P (precoce) e T (Tardio).

aproximadamente 200m da área experimental, com registros da temperatura do ar e radiação solar a cada 15 minutos. A temperatura média diária do ar foi calculada pela média aritmética dos 96 registros diários de temperatura do ar registrados pela estação. A soma térmica diária (STd, ${ }^{\circ} \mathrm{C}$ dia-1), a partir da emergência, foi calculada de acordo com STRECK et al. (2007): Quando a Tb>Tmed $>$ Tmax; $\mathrm{STd}=0$

Se a $\mathrm{Tb} \leq \mathrm{Tmed} \leq \mathrm{Totm}$;

Se a Totm $\leq$ Tmed $\leq$ Tmax; $S T d=\frac{(T \max -T m e d) \times(T o t m-T b)}{(T \max -T o t m)} \times 1$ dia $(3)$ Em que: Tmed é a temperatura média do ar, Totm é a temperatura em que o crescimento da cultura é máximo, Tmax é a temperatura máxima do ar, a partir da qual o desenvolvimento da cultura foi considerado nulo, sendo $\mathrm{Totm}=28^{\circ} \mathrm{C} \mathrm{e} \mathrm{Tmax}=36^{\circ} \mathrm{C}$ (CUTFORTH \& SHAYKEWICH, 1990; STRECK et al., 2008); Tb é a temperatura base, considerada $\mathrm{Tb}=10^{\circ} \mathrm{C}(\mathrm{LOZADA} \&$
ANGELOCCI, 1999). A soma térmica acumulada (STa, ${ }^{\circ} \mathrm{C}$ dia $^{-1}$ ), a partir do dia de emergência, foi calculada por meio do somatório dos valores de STd, conforme equação:

$\mathrm{STa}=\Sigma \mathrm{STd}$

A estimativa do filocrono foi realizada através de regressão linear simples entre o NFE e a STa a partir da emergência. $O$ filocrono para cada parcela (média de duas plantas) foi estimado pelo inverso do coeficiente angular da regressão linear entre NFE e STa (STRECK et al., 2005, 2007). O filocrono foi calculado com base no NFE por coincidir com a escala de desenvolvimento da cultura do milho (RITCHIE et al. 1993). O valor de filocrono obtido para cada repetição e as médias dos híbridos em cada ano foram comparadas pelo teste de Scott-Knott em nível de 5\% de probabilidade de erro. Para os híbridos que se repetiram entre os anos agrícolas, foram comparados às médias 
dos anos agrícolas de cada híbrido pelo teste t em nível de probabilidade de $5 \%$.

\section{RESULTADOS E DISCUSSÃO}

Durante o período de emissão de folhas, a temperatura média do ar apresentou valores médios diários de $22,8^{\circ} \mathrm{C}, 22,5^{\circ} \mathrm{C} \mathrm{e} 23,6^{\circ} \mathrm{C}$, respectivamente, para os anos de 2007/08, 2008/09 e 2009/10 (Figura 1A). Em todos os anos agrícolas, a Tmed do ar ficou acima da Tb e abaixo da Totm. A Tmax ultrapassou os $36^{\circ} \mathrm{C}$, em um dia no ano agrícola de 2007/08 e dois dias no ano agrícola de 2008/09. Os menores valores de temperatura mínima diária do ar foram de $7,0^{\circ} \mathrm{C}$, e o número total de dias com temperatura mínima do ar abaixo da $\mathrm{Tb}\left(10^{\circ} \mathrm{C}\right)$ foram três para o ano agrícola de 2007/08. Para os anos agrícolas de 2008/09 e 2009/10, a temperatura mínima do ar ficou acima da Tb (Figura 1B).

Os valores médios de densidade de fluxo de radiação solar global incidente durante o período de emissão de folhas (emergência até o pendoamento) foram de 549,9, 502,0 e 444,7 Wm $\mathrm{Wia}^{-1}$, para os anos

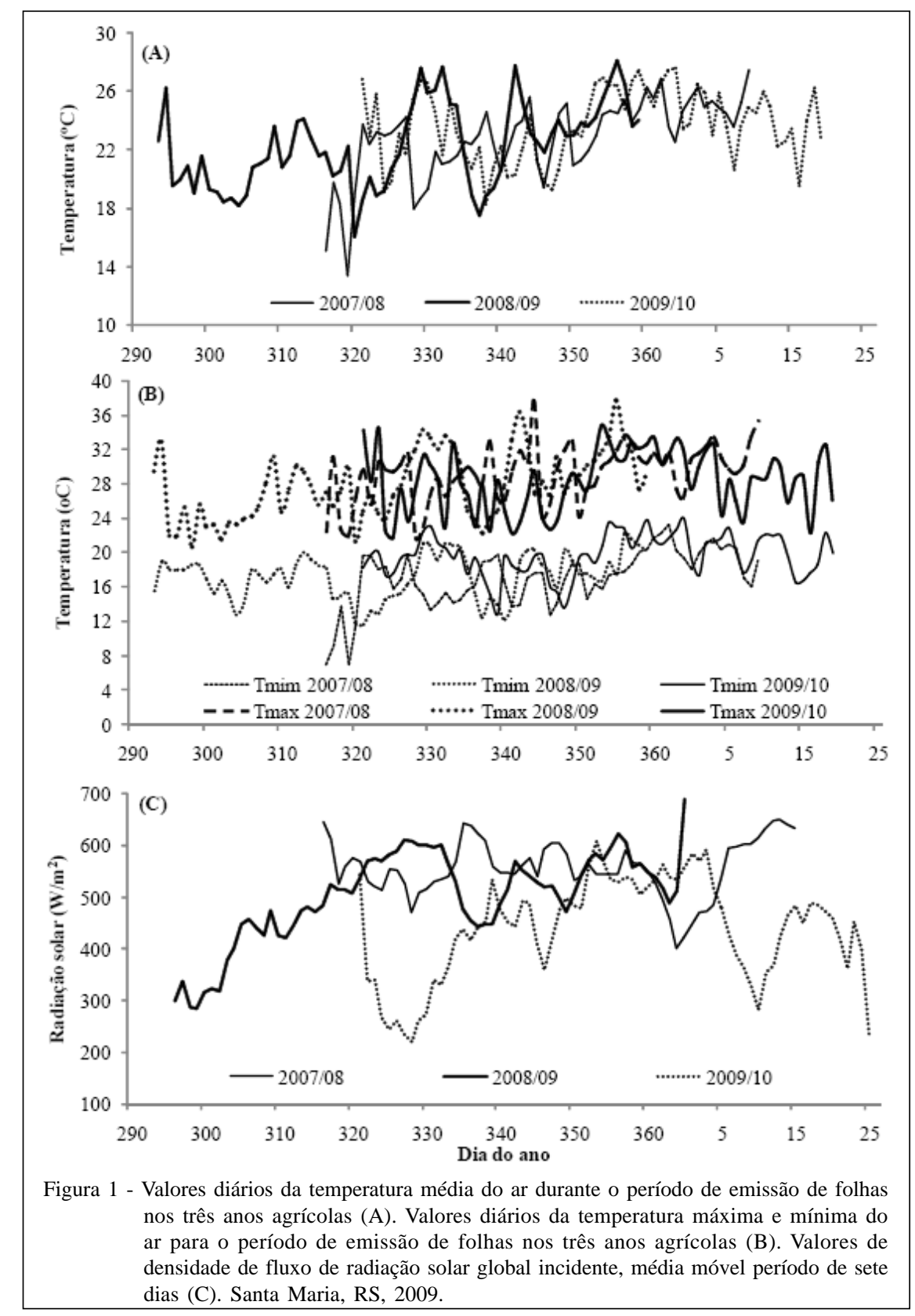

Ciência Rural, v.42, n.5, mai, 2012. 
agrícolas 2007/08, 2008/09 e 2009/10, respectivamente. Os menores valores de densidade de fluxo de radiação solar global incidente, observados em 2009/10, ocorreram devido ao maior número de dias com nebulosidade, devido ao maior número de dias com chuva durante o período de emissão de folhas, que foram 29 dias para o ano agrícola de 2009/10 e de 16 e 18, respectivamente, para os anos 2007/08, 2008/09.

Elevada correlação foi observada entre o NFE e a STa para todos os híbridos avaliados, com coeficientes de determinação $\left(R^{2}\right)$ superiores a 0,95 nos três anos agrícolas (Tabela 1). A relação entre o número de folhas acumuladas e a soma térmica (STa), para o híbrido P3646 no ano agrícola de 2008/09, é apresentado na figura 2A. Essa alta relação linear indica que a emissão de folhas em milho é altamente influenciada pela temperatura.

As médias obtidas para a variável filocrono foram de $37,5,40,6$ e $41,8^{\circ} \mathrm{C}$ dia $^{-1}$ folha ${ }^{-1}$ para os anos agrícolas de 2007/08, 2008/09 e 2009/10, respectivamente. Amédia geral do filocrono obtida neste estudo foi $40,2^{\circ} \mathrm{C}$ dia $^{-1}$ folha ${ }^{-1}$, enquanto STRECK et al. (2009) obteve valores médios de 55,7 e 53,9 $9^{\circ} \mathrm{C}^{-1}$ dia folha ${ }^{-1}$, para a cultivar 'BRS Missões', em sete épocas de semeadura, em dois anos agrícolas (2005/06 e 2006/07), respectivamente. O maior valor obtido por STRECK et al. (2009) pode ser atribuído às distintas metodologias utilizadas para calcular o filocrono, já que foi adotado $\mathrm{Tb}=8^{\circ} \mathrm{C}$ em STRECK et al. (2009), além da influência das condições ambientais e de diferente híbrido utilizado. Entretanto, SCHONS et al. (2009), usando uma Tb de $10^{\circ} \mathrm{C}$ para o mesmo híbrido utilizado por STRECK et al. (2009), encontrou valores de filocrono de $41,5^{\circ} \mathrm{C}^{-1}$ dia folha ${ }^{-1}$, muito próximo a média observada neste estudo.

Os valores de filocrono apresentaram diferenças entre genótipos de milho (Tabela 1). Esta variação de filocrono observada entre alguns genótipos pode representar implicações práticas, como a previsão

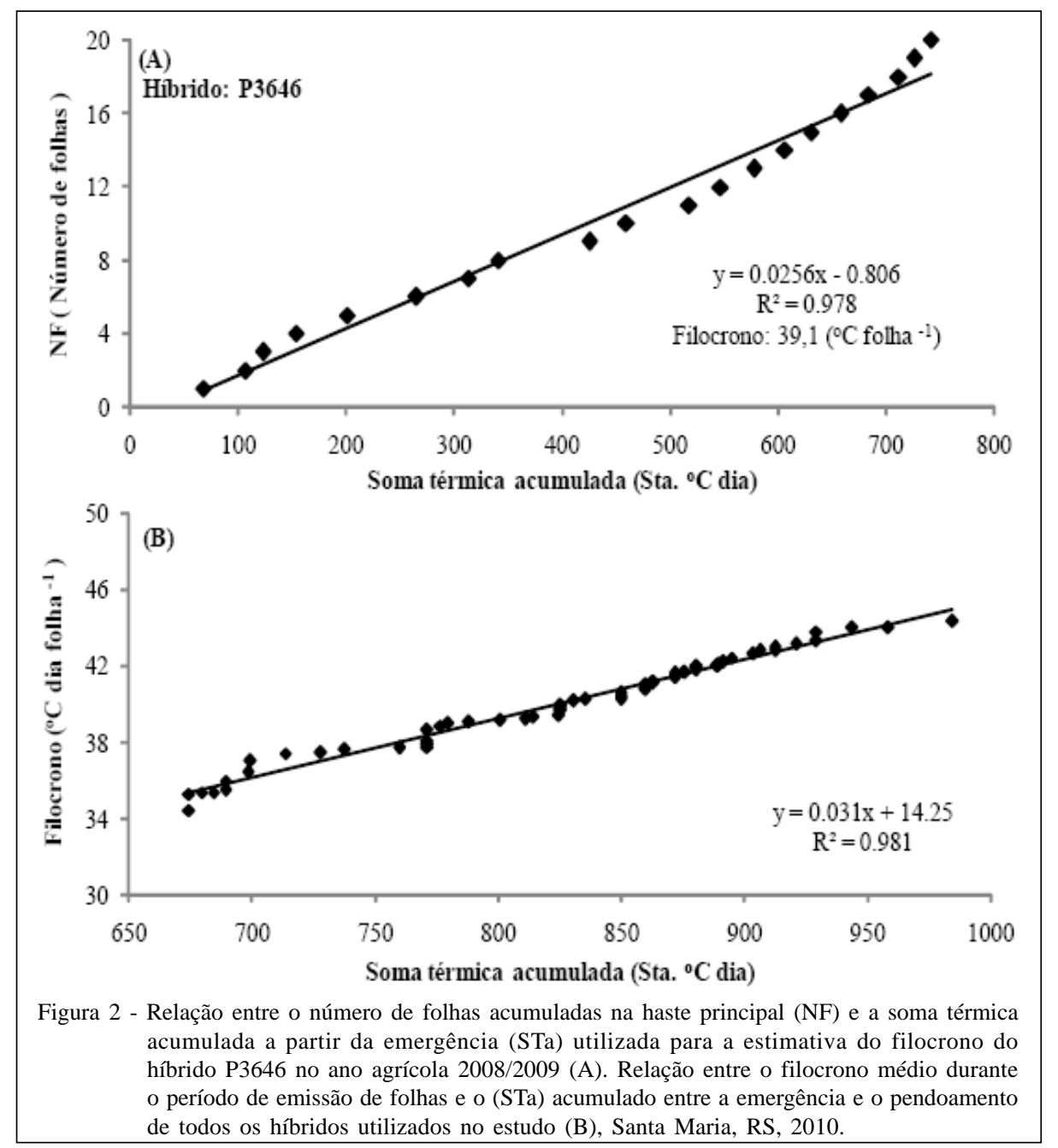

Ciência Rural, v.42, n.5, mai, 2012. 
da data de florescimento. Considerando os híbridos 2B587 e 2A120 no ano agrícola de 2007/08 e seus respectivos valores de filocrono de 40,2 e $34,4^{\circ} \mathrm{C}^{-1}$ dia folha ${ }^{-1}$, tem-se uma diferença entre os híbridos de $5,8^{\circ} \mathrm{C}^{-1}$ dia folha ${ }^{-1}$. Supondo que esses híbridos emitam 20 folhas, com uma STd de $13^{\circ} \mathrm{C}^{-1} \mathrm{dia}^{-1}$ (Temperatura média do ar de $23^{\circ} \mathrm{C}$ ), tem-se aproximadamente 8,9 dias do calendário civil de diferença para a data de emissão da vigésima folha (florescimento). Portanto, para fins práticos de simulação de previsão da data de florescimento de híbridos de milho, deve-se considerar a diferença de filocrono entre os genótipos.

No presente estudo, foi testada a hipótese de que o filocrono varia em função da precocidade de cada híbrido para atingir o florescimento, pois, quando são comparados os valores de filocrono entre os híbridos para cada ano agrícola, observa-se que os híbridos podem ser classificados em grupos pelo teste de Scott-Knott (Tabela 1). Esta diferença pode estar associada ao ciclo de desenvolvimento de cada híbrido, pois, ao relacionar o filocrono de cada híbrido com a sua STa durante a fase vegetativa (emergência até o pendoamento), observa-se uma resposta linear positiva, com elevado coeficiente de correlação $\left(\mathrm{R}^{2}=0,97\right)$ (Figura 2B). Portanto, pode-se afirmar que híbridos precoces apresentam maior velocidade de emissão de folhas que híbridos tardios.

Considerando a classificação de FANCELLI \& DOURADO-NETO (2000), que classificam os híbridos de milho quanto a STa durante a fase vegetativa, em que híbridos que requerem de 780 a 830 $\left(\mathrm{STa}^{\circ} \mathrm{C}\right.$ dia $\left.^{-1}\right)$ para atingir o florescimento são considerados superprecoces; precoces de 831 a 890 $\left(\mathrm{STa}^{\circ} \mathrm{C}\right.$ dia $\left.^{-1}\right)$; e tardios de 891 a $1.200\left(\mathrm{STa}^{\circ} \mathrm{C} \operatorname{dia}^{-1}\right)$. Assim, pode-se atribuir valores de filocrono para diferentes grupos de híbridos, considerando sua precocidade quanto ao florescimento. Híbridos tardios apresentam filocrono médio de $42,2^{\circ} \mathrm{C}$ dia $^{-1}$ folha ${ }^{-1}$ (média dos híbridos com STa ${ }^{\circ} \mathrm{C} \operatorname{dia}^{-1}$ de 891 a 1200), precoces de $41,1^{\circ} \mathrm{C}$ dia $^{-1}$ folha ${ }^{-1}$ (média dos híbridos com $\mathrm{STa}^{\circ} \mathrm{C}$ dia $^{-1}$ de 831 a 890), superprecoces de $39,8^{\circ} \mathrm{C}$ dia ${ }^{1}$ folha $^{-1}$ (média dos híbridos com STa ${ }^{\circ} \mathrm{C} \mathrm{dia}^{-1}$ de 780 a 830) e híbridos que necessitam de menos $780\left(\mathrm{STa}^{\circ} \mathrm{C}\right.$ $\mathrm{dia}^{-1}$ ) para atingir o florescimento apresentam filocrono médio de $36,3^{\circ} \mathrm{C}$ dia $^{-1}$ folha ${ }^{-1}$, podendo ser considerados como híbridos hiperprecoces. Sendo assim, modelos de simulação de fenologia de milho devem considerar a precocidade de cada híbrido para atingir o florescimento, pois esta característica está relacionada com a velocidade de emissão de folhas em milho.

Somente dez híbridos dos 53 utilizados se repetiram em mais de um ano agrícola. O híbrido (AG8021), nos anos agrícolas de 2007/08 e 2009/10, o híbrido (AS1565), nos anos agrícolas de 2007/08 e 2008/ 09, e os híbridos (30B39, 30S31, AG8011, BG7049, BG7055, BG7060, P3646, P3862), nos anos agrícolas 2008/09 e 2009/10. Não foram encontradas diferenças significativas entre as médias dos valores de filocrono dos híbridos que se repetem entre os anos agrícolas pelo teste $\mathrm{t}(\mathrm{P}<0,05)$ (Tabela 1$)$. As diferenças nas médias do filocrono entre os anos agrícolas nos quais os híbridos se repetem foram de $0,1,0,2,0,3,0,4,1,0,1,8$, 1,7, 1,6, 1,4 e 2,3 ${ }^{\circ} \mathrm{C} \mathrm{dia}{ }^{-1}$ folha ${ }^{-1}$, respectivamente, para os híbridos BG7049, BG7055, 30B39, P3646, P3862, AG8021, AG8011, BG7060 30S31 e AS1565. Entretanto, a maioria dos híbridos que se repetiram nos anos agrícolas (AG8021, 30S31, AG8011, BG7049, BG7055, BG7060, P3646) apresentou maiores valores de filocrono no ano agrícola 2009/10, em comparação com os outros dois anos agrícolas (2007/08 e 2008/09). Os maiores valores de filocrono no ano agrícola de 2009/10 podem ser atribuídos ao menor fluxo de radiação solar global observado neste ano (Figura 1C), resultando em desenvolvimento vegetativo mais lento dos híbridos. Resultados semelhantes foram encontrados por HELDWEIN et al. (2010) que observaram redução na velocidade de emissão de folhas com a redução da radiação solar.

\section{CONCLUSÃO}

O filocrono calculado variou de 44,3 a $34,4^{\circ} \mathrm{C}$ dia $^{-1}$ folha ${ }^{-1}$ entre os híbridos avaliados, estando o valor de filocrono diretamente relacionado com a precocidade do período vegetativo, sendo de $36,3^{\circ} \mathrm{C}$ dia $^{-1}$ folha ${ }^{-1}$ para híbridos hiperprecoces; $39,8^{\circ} \mathrm{C} \mathrm{dia}^{-1}$ folha $^{-1}$ para superprecoces; $41,1^{\circ} \mathrm{C}$ dia $^{-1}$ folha $^{-1}$ para precoces e $42,2^{\circ} \mathrm{C} \mathrm{dia}^{-1}$ folha $^{-1}$ para tardios.

\section{REFERÊNCIAS}

ALLEN, R.G.et al. Evapotranspiración del cultivo: guías para la determinación de los requerimientos de água de los cultivos. Roma: FAO-56, 2006. 298p.

BERGAMASCHI, H.; MATZENAUER, R. Parte II - Cultivos temporários: milho. In: Instituto Nacional de Meteorologia. INMET. (Org.). Agrometeorologia dos cultivos $O$ fator meteorológico na produção agrícola. Brasília: INMET, 2009. p.240-260.

COMISSÃO DE QUÍMICA E FERTILIDADE DO SOLO - RS/ SC. Manual de adubação e calagem para os Estados do Rio Grande do Sul e Santa Catarina. 10.ed. Porto Alegre: SBCS- NRS, 2004. 394p.

CUTFORTH, H.W.; SHAYKEWICH, C.F. A temperature response function for corn development. Agricultural and Forest Meteorology, v.50, p.159-171, 1990. 
FANCELLI, A.L.; DOURADO-NETO, D. Produção de milho. Guaíba: Agropecuária, 2000. 360p.

FORSTHOFER, E.L. et al. Desenvolvimento fenológico e agronômico de três híbridos de milho em três épocas de semeadura. Ciência Rural, v.34, p.1341-1348, 2004 Disponível em: <http://www.scielo.br/pdf/cr/v34n5/ a04v34n5.pdf>. Acesso em: 10 mar. 2011. doi:10.1590/S01034782004000500004

HELDWEIN, A.B. et al. Plastocrono e rendimento de feijãode-vagem cultivado sob ambiente protegido e no ambiente externo em semeadura tardia no outono. Ciência Rural, v.40, n.4, p.768-773, 2010. Disponível em: <http://www.scielo.br/ pdf/cr/v40n4/a522cr2466.pdf >. Acesso em: 15 jun. 2011. doi: 10.1590/S0103-84782010005000045.

LOZADA, B.I.; ANGELOCCI, L.R. Determinação da temperatura-base e de graus-dia para estimativa da duração do subperíodo da semeadura à floração de um híbrido de milho. Revista Brasileira de Agrometeorologia, v.7, n.1, p.3136, 1999.

McMASTER, G.S. et al. Simulation of shoot vegetative development and growth of unstressed winter wheat. Ecological Modelling, v.53, p.189-204, 1991. Disponível em: <http://digitalcommons.unl.edu/ cgi/viewcontent.cgi?article $=1099 \&$ context=usdaarsfacpub $>$. Acesso em: 09 mar. 2011.

NESMITH, D.S.; RITCHIE, J.T. Short - and long - term responses of corn to a pre anthesis soil water deficit. Agronoy Journal, v.84, p.107-113, 1992.

RITCHIE, S.W. et al. How a corn plant develops. Ames: Iowa State University of Science and Technology/Cooperative Extention Service, 1993. 21p. (Special Report, 48).

SCHONS, A. et al. Arranjos de plantas de mandioca e milho em cultivo solteiro e consorciado: crescimento, desenvolvimento e produtividade. Bragantia, v.68, p.155-167, 2009. Disponível em: <http://www.scielo.br/pdf/brag/v68n1/a17v68n1.pdf>. Acesso em: 10 mar. 2011. doi: 10.1590/S000687052009000100017.

SOLER, C.M.T. et al. Thermal time for phenological development of four maize hybrids grown o?-season in a subtropical environment. Journal of Agricultural Science, v.143, p.169-182, 2005. Disponível em: <http://journals.cambridge.org/action/ displayAbstract?fromPage $=$ online\&aid=321329 $>$ Acesso em: 19 jul. 2011

STRECK, N.A. et al. Estimativa do plastocrono em meloeiro (Cucumis melo L.) cultivado em estufa plástica em diferentes épocas do ano. Ciência Rural, v.35, n.6, p.1275-1280, 2005. Disponível em: <http://www.scielo.br/pdf/cr/v35n6/ a08v35n6.pdf $>$. Acesso em: 11 mar. 2011. doi: 10.1590/S010384782005000600008 .

STRECK, N.A. et al. Simulating the development of field grown potato (Solanum tuberosum L.). Agricultural and Forest Meteorology, v.142, p.1-11, 2007. Disponível em: <http:// www.sciencedirect.com/science/article/pii/S0168192306002826. Acesso em: 11 mar. 2011.

STRECK, N. A. et al. Simulating maize phenology as a function of air temperature with a linear and a non-linear model. Pesquisa Agropecuária Brasileira, v. 43, p. 449-455, 2008. Disponível em: <http://www.scielo.br/pdf/pab/v43n4/ a02v43n4.pdf $>$. Acesso em: 11 mar. 2011. doi: 10.1590/S0100204X2008000400002.

STRECK, N.A. et al. Temperatura base para aparecimento de folhas e filocrono da variedade de milho BRS Missões. Ciência Rural, v.39, n.1, p.224-227, 2009. Disponível em: <http:// www.scielo.br/pdf/cr/v39n1/a35v39n1.pdf>. Acesso em: 11 mar. 2011. doi: 10.1590/S0103-84782009000100035.

XUE, Q. et al. Predicting leaf appearance in field-grown winter wheat: evaluating linear and non-linear models. Ecological Modelling, v.175, p.261-270, 2004. 